results on expansion seem to indicate that any change in hydration accompanying a temperature change is similar for the chlorides, and also for the nitrates, of these three metals. Whether or not this relation extends to other salts than the nitrates and chlorides is, of course, a matter of conjecture.

Index of Refraction of Solutions.-The curves (Fig. 9) showing this property for the normal solutions of the nitrates and chlorides are nearly parallel. This is, of course, to be expected, assuming ionization, for the same reason that the curves for the specific gravity of the same solutions are nearly parallel. The indices for the half normal solutions are approximately the mean between the indices of the corresponding normal solutions and the index of pure water. Rubidium is slightly below the mean of potassium and cesium, and sodium is practically identical with potassium in every case. The position of ammonium in this instance, as was mentioned above, is close to rubidium.

In conclusion, the writer desires to express his thanks to Professor H. W. Foote, under whose direction the above investigation has been carried out, and whose suggestions and criticism have been invaluable.

SHEFPIELD CHEMICAL IABORATORY OF YALE UNIVERSITY,

New Haven, Conn., June, 1912.

\title{
ON THE DECOMPOSITION OF METHYLENE IODIDE AND ITS BEARING ON THE CONSTITUTION OF STEEL.
}

By Edward D. Campeeld and Henry S. Rawdon.

Received July 1, 1912.

In a recent article, "Decomposition of Bromoform,"1 George ]. Sargent, working under the direction of W. D. Bancroft of Cornell University, has endeavored to demonstrate experimentally that the hypothesis proposed by one of the authors to account for the constitution of the carbides of iron, is unnecessary. Briefly this hypothesis is-that iron may form a number of carbides of the general formula $\mathrm{C}_{n} \mathrm{Fe}_{3 n}$, instead of a single carbide, $\mathrm{CFe}_{3}$, as is usually assumed; that when the carbides of iron are dissolved in diluted hydrochloric or sulfuric acid, the first product of solution is the analogous olefin $\mathrm{C}_{n} \mathrm{H}_{2 n}$, together with ferrous chloride or sulfate and hydrogen, and that as products of secondary reaction between the "nascent" olefins and nascent hydrogen there will result the corresponding paraffins $\mathrm{C}_{n} \mathrm{H}_{(2 n+2)}$, together with more or less liquid or solid products formed by the polymerization of unsaturated hydrocarbons of relatively high molecular weight.

It is a little unfortunate that Sargent seems to have so little familiarity with the literature bearing on the constitution of steel, as a little deeper knowledge of that subject might have rendered the publication of his

${ }^{1}$ J. Physic. Chem., I6, 407. 
work unnecessary. That the idea of the existence of more than one carbide of iron is not a new one is shown by the following quotation: "The earliest evidence as to the condition in which carbon exists in iron was that adduced by Faraday, who, in 1822 , established the fact that at least two different conditions existed in quenched and annealed steel respectively: the former dissolving in dilute hydrochloric acid, while the latter left a carbonaceous residue. Caron worked on similar lines and showed that rolled steel gave a larger amount of carbonaceous residue than hammered, and stated that the amount obtainable was proportional to the time of annealing. Rinman in 1865 proposed to assign names to the two forms of carbon existing respectively in quenched and worked steel and in blister and unworked (annealed) steel. To the first he gave the name "hardening" carbon and to the second "cement" carbon. Karsten also recognized those forms and also graphite. He regarded cement carbon as a polycarbide of iron. This idea of the existence of carbides of iron has long prevailed in the minds of chemists. Berthier was of the opinion that a carbide, $\mathrm{CFe}$, existed, and Berzelius believed in the existence of carbides $\mathrm{FeC}_{2}$ and $\mathrm{Fe}_{2} \mathrm{C}_{3}$. Karsten, moreover, supposed the condition of the carbides in hardened steel to be identical with the polycarbides of white iron. The existence of a definite carbide of iron in annealed steel and white iron was first established by $\mathrm{Abel}$, who, by means of chromic acid solutions, isolated a carbide of the general composition $\mathrm{Fe}_{3} \mathrm{C}^{\prime \prime}$. The carbide $\mathrm{CFe}_{3}$ was described by Abel. ${ }^{2}$ Since that time most metallurgical chemists have contented themselves with the simple formula $\mathrm{CFe}_{3}$ containing but a single carbon atom to the molecule, and have been unwilling to accept a conception of the constitution of steel which would involve the necessity of considering the molecular weights of the carbides. As at the present time we have no means of determining the molecular weights of substances in the solid form or in solid solution, the probable molecular weight of the carbides of iron has been deduced from the products of solution in acids. It is to this method of inferring the relative molecular weights of the carbides of iron that Sargent objects, claiming that a much simpler explanation of the occurrence of the series of olefins and paraffins would be to assume the existence of but one carbide of iron, $\mathrm{CFe}_{3}$, yielding as its primary product of solution $\mathrm{CH}_{2}, \mathrm{FeCl}_{2}$ and hydrogen, and that all the series of olefins are formed by polymerization of $\mathrm{CH}_{2}$. Even Sargent's hypothesis that: "A simpler and, at present, more probable explanation for the products obtained by the decomposition of iron carbide by $\mathrm{HCl}$ is that the first products of the decomposition are hydrogen, $\mathrm{FeCl}_{2}$ and $\mathrm{CH}_{2}$. This $\mathrm{CH}_{3}$ is liberated in the so-called nascent state and in the very probable presence of catalytic agents. It is also incapable of

"Harbord, "Metallurgy of Steel," Vol. I, p. 342, latest edition.

"Proc. Inst. Mech. Eng, 1885 , 
existing alone. Under these conditions it polymerizes into $\mathrm{C}_{2} \mathrm{H}_{4}, \mathrm{C}_{3} \mathrm{H}_{6}, \mathrm{C}_{8} \mathrm{H}_{8}$, etc.,"-is not original with him, for in I9Io Otto Werkmeister ${ }^{1}$ describes the results obtained on dissolving some nearly pure carbides of iron in acids. Werkmeister's research like that of Sargent was largely suggested by the results published by one of us in $x 896$, and Werkmeister, like Sargent, seems to have been unaware of two later publications "On Constitution of Steel"' and "The Constitution of Carbon Steels." 3 Werkmeister prepared nearly pure carbides of iron and obtained, by analysis of the products of solution, results which confirmed experimentally those obtained in this laboratory more than sixteen years ago. As, however, there seemed to be some variations due to differences of conditions of solution of the carbides, he suggests the same hypothesis now advanced by Sargent--that the primary products are $\mathrm{CH}_{2}$ and hydrogen and that the hydrocarbons of higher molecular weight are all derived from polymerization and hydrogenation of $\mathrm{CH}_{2}$.

A working hypothesis should serve as a basis for experimental work offering an explanation for as many observed phenomena as possible without being contradictory to any known fàct. As the result of about eight years' study of the products of solution of steel in this laboratory, two principal facts seem to be clearly demonstrated: Ist, that there is a close relationship between the molecular weight of the hydrocarbons evolved on solution of steel and the carbon concentration in the steel; 2nd, that with a given carbon concentration, there is a close relationship between the molecular weight of the hydrocarbons evolved and the heat treatment of the steel. It was demonstrated that on dissolving annealed steels the mean molecular weight of the hydrocarbons from hypoeutectoid steel, $i$. e., carbon less than $0.90 \%$, was distinctly greater than that of the molecular weights of hydrocarbons evolved from hypereutectoid metal. It was further shown that with a given carbon content in steel the mean molecular weight of the hydrocarbons from the hardened steels was much lower than that from the annealed metal. The details of this work may be found in the article by one of the authors, "On the Constitution of Steel," already referred to.

For more than 30 years steel chemists have recognized the fact that in the colorimetric method for the determination of carbon in steel, in order to obtain concordant results, it is necessary that the standard steel should have approximately the same carbon content and should have undergone the same heat treatment as the unknown. If it were true that there were but one carbide of iron with a single carbon atom to the molecule and that the complex hydrocarbons and nitro derivatives resulted from

${ }^{1}$ Dissertation, "Ueber Bildung und Zerfall von Eisenkarbid und die gasförmigen Produkte der Einwirkung von Mineralsäuren."

$2 J$. Iron Steel Inst., (1899) 2, 223.

Ibid., (1908) No. 3, p. 3 18. 
the polymerization of $\mathrm{CH}_{2}$, it is difficult to conceive why the polymerization of the $\mathrm{CH}_{2}$ should be so closely connected with the carbon concentration and heat treatment when the conditions of solution of the steel are maintained as nearly constant as possible. After a rather full quotation from a publication of one of the authors, Sargent proposes a structural formula of a hypothetical carbide, $\mathrm{C}_{3} \mathrm{~F}_{3}$, constructing this formula in such a way that on solution it would be expected to yield trimethylene, and then because trimethylene is not one of the products of solution of steel assumes the author must be in error. He also proposes a structural formula for the carbide $\mathrm{C}_{4} \mathrm{Fe}_{12}$, which would be expected to yield tetramethylene. A - structural formula is at the best but a means of graphically representing atomic relations which might be expected to yield products of solution in accordance with observed facts. When, therefore, Sargent writes structural formulas which would obviously yield products of solution not in accordance with facts, he is merely setting up strong men to be knocked down by his own reasoning. Structural formulas which would not be in opposition to observed phenomena have been suggested. ${ }^{\text {. }}$

In order to demonstrate that it is unnecessary to assume a higher molecular weight for the carbides of iron than would be indicated by a single carbon atom to the molecule, Sargent has selected the single carbon atom carbide, bromoform $\left(\mathrm{CHBr}_{3}\right)$. On allowing an absolute alcoholic solution of bromoform, to which was added in some cases an amouat of water equal in volume to that of the $\mathrm{CHBr}_{3}$, to react with a zinc-copper couple, he found that varying proportions of $\mathrm{CH}_{4}$ and $\mathrm{C}_{2} \mathrm{H}_{2}$ were produced. So far as can be seen from his published results polymerization of the $\mathrm{CH}$ liberated did not proceed farther than $\mathrm{C}_{2} \mathrm{H}_{2}$. The authority quoted for the polymerization of $\mathrm{C}_{2} \mathrm{H}_{3}$ to form benzene, styrolene, etc., shows that the experiments resulting in such polymerization were carried on at temperatures approaching the softening point of hard glass and therefore reactions taking place under such conditions could not be considered to have much bearing on what would take place in solution at temperatures below $\operatorname{IOn}^{\circ}$. Sargent's conclusions might have had more weight if in his experiments the $\mathrm{CH}$ liberated from the $\mathrm{CHBr}_{3}$ had been formed in an acid solution in the presence of excess of hydrogen, as these are the conditions under which the hydrocarbons derived from a solution of steel are formed.

When one of the authors in 1896 suggested the probable existence of a series of carbides of the general formula $\mathrm{C}_{n} \mathrm{Fe}_{3 n}$, in order to account for the products of solution, he assumed that $\mathrm{CH}_{2}$ if liberated in acid solution in presence of nascent hydrogen would either be completely converted to $\mathrm{CH}_{4}$ or if polymerization took place at all it would not go beyond the formation of $\mathrm{C}_{2} \mathrm{H}_{4}$, which latter might be reduced to $\mathrm{C}_{2} \mathrm{H}_{8}$. This idea was, we believe, generally held by organic chemists of that time. That this 
idea is still held by most organic chemists is illustrated by the following:" "All halogen derivatives of marsh gas are converted into marsh gas by nascent hydrogen, generated in some suitable manner;" also, "The olefins are converted into paraffins by nascent hydrogen." Again, Nef makes the following statement: "Methyl iodide and sodium produce first $\mathrm{CH}_{2}$ and $\mathrm{HI}$ and the $\mathrm{HI}$ is then changed by the sodium into $\mathrm{NaI}$ and nascent hydrogen: $\quad \mathrm{CH}_{3} \mathrm{I}+\mathrm{Na}=\mathrm{CH}_{2}+\mathrm{HI}+\mathrm{Na}=\mathrm{CH}_{2}+\mathrm{NaI}+\mathrm{H}$. The quantity of nascent hydrogen produced under these conditions does sot suffice to change methylene completely over into $\mathrm{CH}_{4}$ (this is, however, not the case in presence of zinc and water or when the $\mathrm{Zn}$-Cu couple and alcohol is used, as here zinc produces nascent hydrogen either with water or alcohol as the case may be, and there is therefore obtained $\mathrm{CH}_{4}$ ). One part of the nascent $\mathrm{CH}_{2}$ will therefore take up only one atom of hydrogen, $\mathrm{CH}_{2}+\mathrm{H}=\mathrm{CH}_{3}$, and the methyl thus formed polymerizes to dimethyl, $\mathrm{C}_{2} \mathrm{H}_{6}$, another part of the methylene polymerizes simply to ethylene, while the formation of $\mathrm{CH}_{4}$ by the reduction of $\mathrm{CH}_{3} \mathrm{I}$ (and perhaps of $\mathrm{CH}_{2}$ ) with free hydrogen is entirely possible."

As Werkmeister, in 1910, advanced the same hypothesis for the formation of the series of hydrocarbons as that now put forth by Sargent, it was thought that it might be well to undertake some experiments to determin whether after all $\mathrm{CH}_{2}$ if generated in an acid solution in presence of nascent hydrogen and iron might not polymerize readily into hydrocarbons of high molecular weight and thus account for the various hydrocarbons obtained from steel. A number of experiments were therefore undertaken in the autumn of I9I I to settle this point. It was thought best to make the conditions under which the $\mathrm{CH}_{2}$ would be liberated as nearly as possible those which would obtain during the solution of steel in $\mathrm{HCl}$. At the time the hydrocarbons derived from steel were under examination in this laboratory samples of steel, usually about soo grams at a time, were placed in a large generating flask provided with a perforated stopper through which passed a dropping funnel for introduction of hydrochloric acid and a tube for the escape of the evolved gases. Enough water was placed in the flask at the beginning to just cover the sample, acid was dropped in slowly and the flask heated on a water bath until reaction ceased. The evolved gases were passed through bromine to form the dibrom derivatives of the olefins and the remaining gas (hydrogen and paraffins) was collected in a graduated gasometer. The results of this work have been described more in detail. ${ }^{4}$ In dissolving steel in this way, a considerable amount of heavy hydrocarbons, some solid condensation products, will be formed in the

'Perkin and Kipping, "Organic Chemistry," p. 53.

2 Ibid., p. 79.

3 Ann., 298, 270.

'J. Iron Steel Inst., (1899), 2, 226. 
flask and in the tube of the reflux condenser through which the gas is made to pass. These products have the strong disagreeable odor so familiar to all steel chemists. In the first experiments undertaken, practically chemically pure iron was placed in a generating flask under conditions as nearly as possible the duplicate of those used in the solution of steel. Instead, however, of allowing acid alone to drop into the flask, a second dropping funnel was provided in which was placed a weighed amount of $\mathrm{CH}_{2} \mathrm{I}_{2}$. It was hoped that in this way if $\mathrm{CH}_{2} \mathrm{I}_{2}$ and $\mathrm{HCl}$ were simultaneously introduced, the $\mathrm{CH}_{2} \mathrm{I}_{2}$ would form $\mathrm{CH}_{2}$ and $\mathrm{FeI}_{2}$ which would be in the presence of the nascent hydrogen at the same time evolved from the hydrochloric acid. It was found, however, that pure iron does not react readily with $\mathrm{CH}_{2} \mathrm{I}_{2}$; this latter heavy liquid settled in the bottom of the flask and reaction, as far as $\mathrm{CH}_{2} \mathrm{I}_{2}$ was concerned, ceased. It was found necessary to substitute something which would react with $\mathrm{CH}_{2} \mathrm{I}_{2}$ more readily. An excess of zinc, in the form of shot previously treated with $\mathrm{CuSO}_{4}$, was substituted for the iron. As it was thought that the presence of iron might possibly exert in some way a catalytic influence upon the polymerization of $\mathrm{CH}_{2}$, in a number of experiments some $\mathrm{FeCl}_{3}$ was introduced into the flask and allowed to react until the ferric chloride had been reduced to ferrous chloride before methylene iodide and acid were run in. This was done so that if the presence of iron influenced the polymerization it would be shown. The experiments, however, showed that the presence of iron was without influence upon the reaction. In the earlier experiments the $\mathrm{CH}_{2} \mathrm{I}_{2}$ was dissolved in ether, but this did not seem to influence the reaction so far as the formation of $\mathrm{CH}_{4}$ and $\mathrm{C}_{2} \mathrm{H}_{4}$ went, but the presence of ether prevented the detection of ethyl compounds which might have been derived from $\mathrm{CH}_{2} \mathrm{I}_{2}$, so that in the last experiments the $\mathrm{CH}_{2} \mathrm{I}_{2}$ was introduced in the pure form. In performing an experiment the air in the generating flask was swept out with $\mathrm{CO}_{2}$ before introducing the $\mathrm{CH}_{2} \mathrm{I}_{2}$ and acid. When the air had been displaced hydrochloric acid was allowed to drop in slowly from one funnel and $\mathrm{CH}_{2} \mathrm{I}_{2}$ from a similar one. The flask was kept warm on the water bath so that a brisk evolution of hydrogen ensued. The gases evolved, after passing upward through a reflux condenser, were passed into a large graduated gasometer filled with distilled water. The time required for an experiment was usually from one to two hours and the total volume of gas collected varied from 8 to 18 liters. When all action had ceased the volume of gas in the gasometer was noted, together with temperature and barometric pressure, and reduced to standard conditions. Samples were drawn off and the $\mathrm{CO}_{2}$ originally introduced removed by absorption with potassium hydroxide. The ethylene was determined by absorption in bromine in the usual way, and a small amount of oxygen from the air in the distilled water removed with phosphorus. In no case could any indication of carbon monoxide be obtained. Aliquot 
portions of the residual gas, containing paraffin hydrocarbons, hydrogen, and a small amount of nitrogen from the dissolved air, were then worked in the usual manner in explosion pipettes to determin the volume of $\mathrm{CO}_{2}$ produced, the contraction of volume, and the amount of oxygen required for the combustion. On the assumption that the hydrocarbon present was methane, the volume of this was calculated from the volume of $\mathrm{CO}_{2}$ produced by the explosion. That this assumption was probably correct was shown by taking samples of the gas after removal of all but paraffins, $\mathrm{H}_{2}$ and $\mathrm{N}_{2}$, and passing them into an absorption pipette containing a $\mathrm{I} \%$ solution of palladous chloride and thus determining the hydrogen directly by the method described by one of the authors, ${ }^{1}$ the only modification being the insertion of a stop-cock between the two bulbs in order to prevent diffusion of the gases during the time the solution was heated. After the absorption with palladous chloride, a measured volume of hydrogen was added to a known volume of the gas, mixed with a measured volume of air and exploded. The volume of the $\mathrm{CO}_{2}$ formed, the contraction and the volume of oxygen absorbed were noted. When a sample of the gas was taken directly from the palladous chloride bulb, mixed with air and an attempt made to explode it, there was no combustion. When $5.9 \mathrm{cc} . \mathrm{H}_{2}$ was added to $6.2 \mathrm{cc}$. of the gas, and air added and then exploded, there was $4.2 \mathrm{cc}$. $\mathrm{CO}_{2}$ formed, and a total contraction of $\mathrm{I} 8 . \mathrm{I} \mathrm{cc}$. If we deduct I. 5 times the volume of hydrogen from I8. I, we have $9.2 \mathrm{cc}$. contraction for a volume of $4.2 \mathrm{cc}$. $\mathrm{CO}_{2}$ or $0.8 \mathrm{cc}$. contraction in excess of what would be required for the explosion of pure methane. This excess contraction might be easily accounted for if the absorption of hydrogen with palladous chloride had not been quite complete. If ethane in any considerable quantity had been present the contraction would have been less than twice the volume of $\mathrm{CO}_{2}$ since 2 volumes of $\mathrm{C}_{2} \mathrm{H}_{6}$ with 7 volumes $\mathrm{O}_{2}$ give 4 volumes $\mathrm{CO}_{2}$, so that the contraction would be 5 volumes or I.25 times volume $\mathrm{CO}_{2}$. While not demonstrating conclusively the absence of ethane, since one volume of $\mathrm{C}_{2} \mathrm{H}_{6}$ with one volume of hydrogen will give the same results on explosion as two volumes of $\mathrm{CH}_{4}$, the fact that the contraction of the gas analyzed was slightly in excess of twice the volume of $\mathrm{CO}_{2}$ and that this excess might easily be due to a small amount of unabsorbed hydrogen indicates that $\mathrm{CH}_{4}$ is the principal, if not the only, paraffin hydrocarbon present.

Working in the manner above described the following results which were typical of a number of experiments were obtained by allowing 16.798 grams $\mathrm{CH}_{2} \mathrm{I}_{2}$ and hydrochloric acid to react on excess of zinc until action had ceased. Total volume of gas recovered at standard conditions $=$ I6. I 5 liters. This contained $0.4 \%$ ethylene, which was equivalent to 64.6 cc., and $6.4 \% \mathrm{CH}_{4}$, which equals $1033.6 \mathrm{cc}$.

1 Am. Chem. J., I8, 294 (1896). 


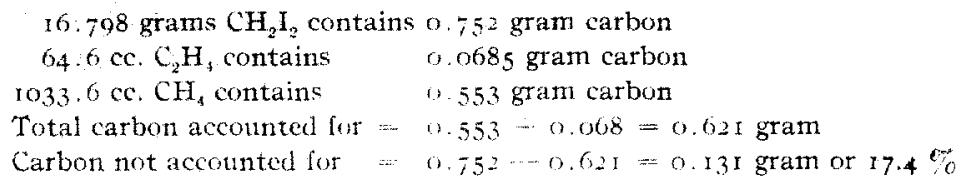

It will thus be seen that more than $82 \%$ of the carbon of the $\mathrm{CH}_{2} \mathrm{I}_{2}$ was found as $\mathrm{C}_{2} \mathrm{H}_{4}$ and $\mathrm{CH}_{4}$, mostly the latter. No sign of dark colored unsaturated condensation products were found in the flask or condenser as is the case when steel is dissolved, and on pouring out the solution of $\mathrm{ZnCl}_{2}$ and $\mathrm{ZnI}_{2}$ from the generating flask it was found to have a "sweetish" rather pleasant odor. About I $50 \mathrm{cc}$. of this solution were placed in a flask, and into each of three similar flasks was placed an equal volume of water. To one was added a few drops of $\mathrm{C}_{2} \mathrm{H}_{5} \mathrm{I}$, to a second a little $\mathrm{C}_{2} \mathrm{H}_{4} \mathrm{Cl}_{2}$, to the third a few drops of gasoline, and to a fourth lask a solution drawn off from a sample of white iron which was being dissolved in sodium acid sulfate and which possessed the odor characteristic of solutions of carburized iron. An attempt was made to keep the intensity of the odor in the four preparations as near to that of the solution from the generating. flask as possible. The four flasks were then numbered and four different men-two specialists in organic chemistry, one in technological and one in analytical-were requested to arrange the flasks in order of resemblance of odor to that of the solution in the generating flask. Although the contents of each flask were unknown to the operators at the time of making comparisons, three out of four placed the $\mathrm{C}_{2} \mathrm{H}_{5} \mathrm{I}$ as nearest, with $\mathrm{C}_{2} \mathrm{H}_{4} \mathrm{Cl}_{2}$ next, while one placed $\mathrm{C}_{2} \mathrm{H}_{4} \mathrm{Cl}_{2}$ nearest with $\mathrm{C}_{2} \mathrm{H}_{5} \mathrm{I}$ second. All four agreed that the odor of the gasoline and solution from the white iron were of markedly different quality from that of the other two.

These experiments would seem to confirm pretty conclusively the reaction that most organic chemists would expect when $\mathrm{CH}_{2}$ is generated in an acid solution in the presence of nascent hydrogen, $i . c$., most of the $\mathrm{CH}_{2}$ would combine with hydrogen to form methane though a portion might be expected to polymerize forming ethylene, which latter might partly escape in gaseous form and partly remain in solution as ethyl or ethylene compounds, but that the polymerization of such $\mathrm{CH}_{2}$ as does not form $\mathrm{CH}_{4}$ does not go beyond the formation of a two carbon atom molecule.

If, then, $\mathrm{CH}_{2}$ does not tend to polymerize and form hydrocarbons of high molecular weight, it would seem necessary to modify the conception held by most metallurgical chemists of the constitution of the carbide of iron, $i$. e., the carbide of iron has the simple formula $\mathrm{CFe}_{3}$, and to adopt some working hypothesis which is not contrary to fact. The simpler a working hypothesis can be made and yet give reasonable explanation for most observed facts without being in opposition to any, the more satisfactory such a hypothesis will be. At the time the hypothesis of a 
series of carbides, $\mathrm{C}_{n} \mathrm{Fe}_{3 n}$, was first advanced, it was thought that the metallographic constituent cementite probably consists of a mixture of carbides whose composition is approximately expressed by the general formula $\mathrm{C}_{n} \mathrm{Fe}_{3 n}$, yet it is entirely possible that the true constitution of the carbides occurring in iron may not be represented by such a simple formula. The important point in this research, we feel, is the recognition by metallurgical chemists of the fact that the element carbon does not lose its characteristic property of forming complex molecules in which carbon is linked to carbon because the other "bonds," which in the case of hydrocarbons are taken up by hydrogen, in the case under discussion are taken up by iron or other metals.

It is becoming rather well recognized by metallurgical chemists that the physical properties of iron and of ten of many other metals are most profoundly modified by the presence of substances in solid solution, whereas compounds that are mechanically mixed usually impart undesirable properties. The conception that in steel the main part of the iron constitutes a solvent while a portion of the iron is combined with carbon, forming a number of carbides whose constitution and solubility will depend upon the carbon concentration and heat treatment, has formed the basis for experimental research in this laboratory for nearly twenty-two years and so far has not been found contrary to known facts and has offered a reasonable explanation for a number of phenomena not easily explained by the existence of a single carbide of the simple formula $\mathrm{CFe}_{3}$. What little evidence there is seems to point to the probable high molecular weight of the element iron in the solid condition, but until some experimental method for the determination of the molecular weight of solid substances and of substances in solid solution is worked out, many of the problems concerning the relation between the constitution of steel and its physical properties must remain unsolved or their solution must be inferred by indirect methods. If metallurgical chemists, many of whom have had little training along organic lines, could get away from the narrow conception now held by the great majority concerning the chemical relations of iron to carbon and recognize that there is no inherent reason why carbon, which has the property of forming with non-metallic elements such a vast number of complex compounds in which the carbon atoms are linked to each other, should lose its most striking property because these non-metallic elements are replaced by metals, it would make way for a working hypothesis of the constitution of steel which might give some hope of offering a scientific explanation of so many facts connected with the properties of steel, particularly the modern high speed and other special steels. If the similarity of constitution between the carbides of iron and that of organic compounds were recognized the whole problem of the constitution of steel would be reduced to a problem in physical chemistry, and many 
of the laws which have so much value in throwing light on chemical reactions in other lines of work could be employed advantageously in the study of steel. The influence of temperature, pressure, concentration, mass action, velocity of reaction and many other questions could then be studied from the physico-chemical view point; and the iafluence of elements other than iron and carbon on the constitution of solvent or of the solute might be studied with some hope of obtaining reasonable explanations for their influence. The art of controlling the physical properties of steel has usually been in advance of scientific explanation of the reason for the properties of the metal, this being especially true of the properties of the modern alloy steels. Any conception of the constitution of steel to be at all satisfactory must be broad enough to include a possible explanation for the facts now known concerning the properties of this really wonderful metal and should serve as a basis for the further scientific development of the arts.

ChmMical Laboratory, University of Michigan, ANN ARbor, Mich, June 21, 1912.

[CONtribution from the Chemical laboratory of NEW Hampshire COLlege.]

\section{HYDRATES OF LANTHANUM OXALATE.}

BY C. JAMES AND C. F. WhitTEMORE.

Received May 13, 1912.

This work was undertaken in order to ascertain whether the oxalonitrate of lanthanum exists at $25^{\circ}$. For this purpose a careful study of the system, lanthanum oxalate, lanthanum nitrate and water, was carried out, in the usual manner, by adding varying amounts of lanthanum

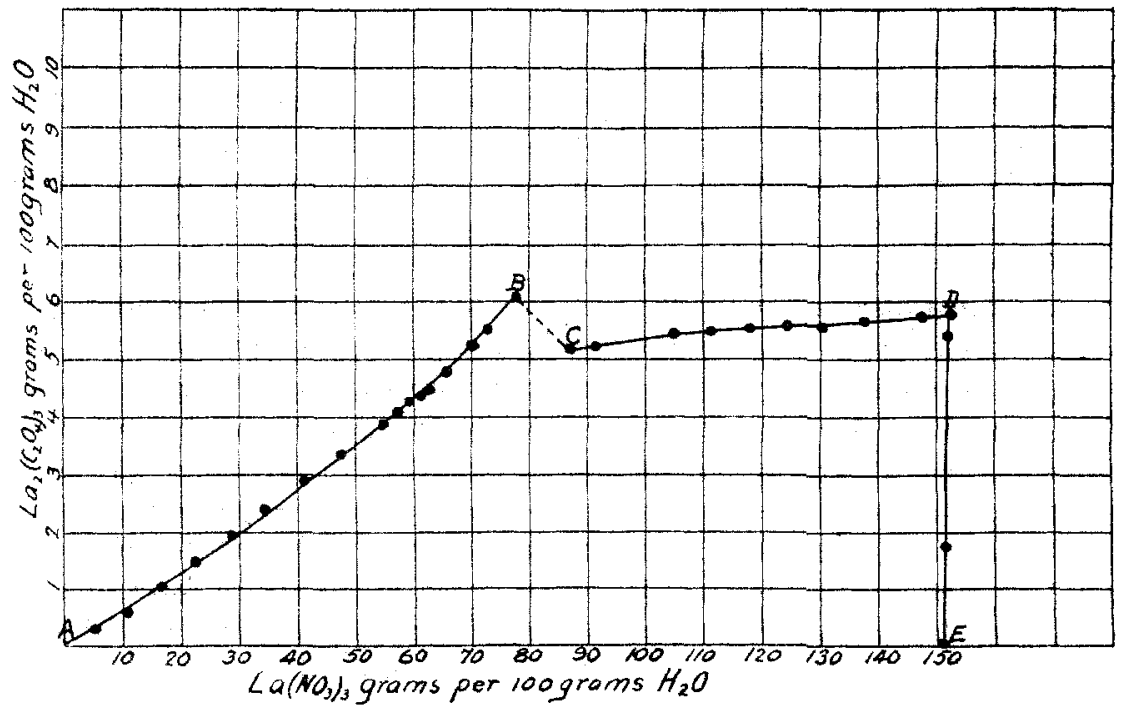

Fig. 1 . 